\title{
Transit Time Heterogeneity in Canine Small Intestine: Significance for Oxygen Transport
}

\author{
Heidi V. Connolly, ${ }^{\star}$ Leigh A. Maginniss, ${ }^{\ddagger}$ and Paul T. Schumacker ${ }^{\S}$ \\ *Department of Pediatrics, The University of Chicago, Chicago, Illinois 60637; ${ }^{\ddagger}$ Department of Biology, DePaul University, Chicago, \\ Illinois 60604; and ${ }^{\S}$ Department of Medicine, The University of Chicago, Chicago, Illinois 60637
}

\begin{abstract}
We previously found that local $\mathrm{O}_{2}$ extraction efficacy in isolated pump-perfused intestine was enhanced when systemic reflex vasoconstriction was stimulated by hypovolemia (Samsel, R.W., and P.T. Schumacker. 1994. J. Appl. Physiol. 77: 2291-2298). The microvascular mechanism underlying this beneficial effect could involve a redistribution of flow between mucosa and serosa, or an adjustment in the heterogeneity of perfusion within those regions. We measured regional blood flows and distributions of flow and capillary erythrocyte transit times in two segments of small intestine in anesthetized dogs $(n=10)$. Each vascularly isolated segment of intestine was pump-perfused under high flow $\left(\mathrm{O}_{2}\right.$ supply-independent $\left.\mathrm{VO}_{2}\right)$ and low flow $\left(\mathrm{O}_{2}\right.$ supply-dependent) conditions. During the first gut segment, the animal was kept normovolemic using i.v. fluids to minimize reflex vasoconstriction. During the second, the animal was hemorrhaged to augment vasoconstriction $(n=7)$, or kept normovolemic to control for the effects of time $(n=3)$. Blood flow distributions were measured using $15 \mu \mathrm{m}$ radiolabeled microspheres. Tissue blood volume was measured using ${ }^{99 \mathrm{~m}} \mathrm{Tc}-$ labeled red blood cells. Capillary volume was determined as the product of tissue blood volume and the histologically derived fraction of vascular volume in the capillaries. Transit times were calculated as the ratio of capillary volume to flow. Each gut segment was fixed and sectioned into $350 \sim 100$ mg tissue pieces for analysis. Data revealed significant spatial heterogeneity of blood flow and capillary transit times in both mucosa and muscularis, with relative dispersions (SD/Mean) ranging from 23 to $97 \%$. Hypovolemia caused an increase in flow heterogeneity in muscularis at both high and low flow states, and in mucosa under high flow conditions. However, hypovolemia also elicited changes in capillary volume, such that transit time heterogeneity remained unchanged. Augmentation of vasoconstrictor tone caused a redistribution of flow toward mucosa $(P<0.003)$ under high and low flow conditions. This redistribution correlated with the improvements in $\mathrm{O}_{2}$ extraction ratio $(P=0.022)$. Thus, the improvement in gut $\mathrm{O}_{2}$ extraction efficacy seen with increased vasoconstriction may be explained mostly by
\end{abstract}

Address correspondence to Paul T. Schumacker, Ph.D., Department of Medicine MC 6026, The University of Chicago, 5841 S. Maryland Ave., Chicago, IL 60637. Phone: 773-702-6790; FAX: 773-702-4736.

Received for publication 7 July 1996 and accepted in revised form 15 November 1996.

J. Clin. Invest.

(C) The American Society for Clinical Investigation, Inc.

0021-9738/97/01/228/11 \$2.00

Volume 99, Number 2, January 1997, 228-238 an intramural redistribution of flow between mucosa and muscularis. Capillary transit time heterogeneity remained unchanged, suggesting that this variable is tightly regulated. (J. Clin. Invest. 1997. 99:228-238.) Key words: capillaries - ischemia - oxygen consumption - microcirculation blood vessels

\section{Introduction}

As oxygen delivery $\left(\mathrm{QO}_{2}\right)^{1}$ to a tissue is reduced, increases in $\mathrm{O}_{2}$ extraction help to maintain its oxygen consumption $\left(\mathrm{VO}_{2}\right)$. However, below a critical delivery the increases in $\mathrm{O}_{2}$ extraction are inadequate to maintain $\mathrm{VO}_{2}$, which becomes limited by $\mathrm{O}_{2}$ supply $(1,2)$. An ability to optimally match microvascular $\mathrm{O}_{2}$ delivery with respect to metabolic need helps to preserve tissue $\mathrm{VO}_{2}$ as $\mathrm{QO}_{2}$ is reduced. If capillary blood flow is not regulated in accordance with $\mathrm{O}_{2}$ needs, some capillaries will be under perfused while others are excessively perfused. When this occurs, normal oxidative metabolism may still continue as long as the overall $\mathrm{QO}_{2}$ remains high. However, if overall $\mathrm{O}_{2}$ delivery were to decrease, cells in relatively poorly perfused regions could become $\mathrm{O}_{2}$ supply-limited at a point where other cells in the tissue were still well supplied.

When systemic $\mathrm{O}_{2}$ delivery is lowered by reducing cardiac output, baroreceptor and volume receptor reflexes augment neurohumoral vasoconstriction in tissues. This response helps to maintain blood pressure and contributes to the redistribution of blood flow among organ systems $(3,4)$. Within tissues, this vasoconstriction contributes to the increases in $\mathrm{O}_{2}$ extraction, presumably by limiting blood flow to capillaries with lesser metabolic demands and preventing a "microvascular steal" of $\mathrm{O}_{2}$ supply (5). When local blood flow to isolated segments of small intestine was reduced by progressively lowering pump speed, we found that local gut $\mathrm{O}_{2}$ extraction ratios reached $69 \%$ at the point where gut $\mathrm{VO}_{2}$ became $\mathrm{O}_{2}$ supply dependent (i.e., the gut critical point) if the animal had been hemorrhaged to activate reflex vasoconstriction (6). However, when neurohumoral vasoconstriction was minimized by administering intravenous fluids to maintain left atrial filling pressure, the local gut $\mathrm{O}_{2}$ extraction ratio only reached $45 \%$ at the critical point.

In a segment of small intestine, reflex vasoconstriction could augment tissue $\mathrm{O}_{2}$ extraction ability by altering the fractional distribution of blood flow between mucosa and muscularis, and/or by altering the spatial distribution of blood flow within each of those layers. Vasoconstriction could also affect capillary transit time by altering capillary blood volume. Such an effect could alter the distribution and heterogeneity of capillary red blood cell transit times, which is a more pertinent

1. Abbreviations used in this paper: $\mathrm{PE}$, polyethylene; $\mathrm{QO}_{2}$, oxygen delivery; $\mathrm{VO}_{2}$, oxygen consumption. 
variable for tissue oxygen supply. This study was designed to quantify the degree of spatial heterogeneity of blood flow and capillary transit times in the normal intestine, and to determine whether a redistribution of blood flow between the layers of the intestine wall or within those layers could explain the previously observed beneficial effect of reflex vasoconstriction on tissue oxygen extraction ability.

\section{Methods}

Surgical preparations. 10 mongrel dogs weighing $25.1 \pm 3.5 \mathrm{~kg}$ were anesthetized with chloralose/urethane (150:750 mg/kg). Supplemental doses of anesthetic were administered periodically to maintain anesthesia. Animals were mechanically ventilated in the supine position with room air using tidal volumes of $15 \mathrm{ml} / \mathrm{kg}$ to achieve an arterial $\mathrm{PCO}_{2}$ in the range of 35-45 Torr. Cannulas were placed in the right femoral artery and vein, and a balloon-tipped catheter was directed into the pulmonary artery via the right external jugular vein. Vascular pressures were measured with strain gauge transducers zeroed at the mid chest level and displayed on a chart recorder. Supplemental intravenous fluids and drugs were delivered using a $60 \mathrm{ml}$ reservoir connected to the right femoral venous cannula and suspended above the animal. Sodium bicarbonate was administered to maintain arterial $\mathrm{pH}$ in the range of 7.35-7.40. Body temperature was measured using a thermistor in the pulmonary artery, and was maintained at $38^{\circ} \mathrm{C}$ with heating pads and warming lamps.

Segments of small intestine were prepared as described in reference 6 . Briefly, a midline laparotomy was performed and a $35-50 \mathrm{~g}$ segment of ileum or jejunum supplied by a single artery and vein was identified. The gut segment was exteriorized and supported on a Plexiglas plate covered with saline saturated gauze. The artery and vein were surgically isolated at the hilum using minimal dissection. Animals were given heparin $(30,000 \mathrm{U}$ i.v. initially, followed by 3,000 $\mathrm{U} / \mathrm{h}$ ) to prevent coagulation in the extracorporeal tubing. The vein was cannulated with a short length of polyethylene (PE) tubing, which was connected to a larger diameter length of silastic tubing used to return venous blood to the animal via the femoral venous reservoir. An ultrasonic flow transducer in the tubing was used to measure blood flow to the segment. A length of tubing in parallel with the flow transducer was used to confirm the electronic zero-flow signal. The artery supplying the segment was cannulated with a short length of PE tubing attached to a luer hub, and the segment was perfused with femoral arterial blood driven either by the dog's arterial pressure (autoperfusion) or by an occlusive roller pump. During autoperfusion, a length of tubing that bypassed the arterial pump was opened; for pump perfusion it was clamped. Gut arterial pressure was monitored at the gut arterial cannula. Gut venous pressure was kept constant by positioning the height of the outflow end of the venous catheter at the level of the table. Venous blood was pumped from a $30 \mathrm{ml}$ reservoir positioned below that point to the femoral venous reservoir. Silk ligatures were then tied tightly at both ends of the gut segment, preventing collateral circulation from adjacent gut regions. Isolation was completed by cauterizing any small vessels in the mesentery. A thermistor was positioned on the surface of the gut segment, which was covered with wet gauze and saran. Gut temperature was maintained at $38 \pm 0.1^{\circ} \mathrm{C}$ by a thermostatically controlled heat lamp. Resistance vessel reactivity was confirmed by occluding gut arterial inflow for 30-40 s. and observing a reactive hyperemia in each animal.

Experimental sequence. During the surgical preparations, animals were administered normal saline intravenously to achieve a pulmonary wedge pressure in the range of $7-10 \mathrm{mmHg}$. This was intended to maintain cardiac output at a high level and to minimize systemic reflex vasomotor tone, as reported in references 6 and 7. After completing the preparations, animals were given bicarbonate solution to adjust arterial $\mathrm{pH}$ and/or dextran solution to adjust pulmonary capillary wedge pressure, if necessary. After allowing $30 \mathrm{~min}$ for the animals to stabilize, baseline measurements of hemodynamics and $\mathrm{O}_{2}$ transport were made while the gut segment was autoperfused (baseline). The gut was then switched to pump perfusion at the same flow rate, an additional 15 min was allowed for stabilization, and measurements were repeated. The distribution of blood flow was then labeled with microspheres (normovolemia, high flow). The gut pump speed was then reduced by an amount to reduce gut $\mathrm{VO}_{2}$ by $25-30 \%$ and to thereby establish $\mathrm{O}_{2}$ supply-limited conditions in the isolated tissue. After 15-20 min at low flow, measurements were repeated and the distribution of gut blood flow was labeled with microspheres containing a second isotope (normovolemia, low flow). Under those same conditions, the blood volume distribution was then labeled with ${ }^{99 \mathrm{~m}} \mathrm{Tc}$-labeled red cells (see below) and the gut segment was clamped and harvested for fixation and analysis.

A second loop of intestine was then exteriorized and prepared in the same manner as the first. Before new baseline measurements, seven of the animals were hemorrhaged incrementally to augment systemic reflex neurohumoral vasoconstriction. Bleeding was stopped when the systemic $\mathrm{O}_{2}$ extraction ratio reached $\sim 60 \%$, thereby maintaining $\mathrm{O}_{2}$ supply independent conditions at the whole body level. This procedure was identical to that used in our previous study (6). After allowing $15 \mathrm{~min}$ to stabilize under autoperfused conditions, baseline measurements were repeated. Perfusion of the gut was then switched to the pump at approximately the baseline flow rate, and hemodynamic, $\mathrm{O}_{2}$ transport measurements, and microsphere injections were repeated after allowing $15 \mathrm{~min}$ to stabilize (hypovolemia, high flow). Again, the gut pump speed was then reduced by an amount aimed to reduce gut $\mathrm{VO}_{2}$ by $\sim 30 \%$ to establish $\mathrm{O}_{2}$ supply-dependent conditions. After allowing $15 \mathrm{~min}$ to stabilize, measurements were repeated and the distribution of gut blood flow was labeled with microspheres containing a second isotope (hypovolemia, low flow). The blood volume distribution was then labeled with ${ }^{99 \mathrm{~m}} \mathrm{Tc}$-labeled red cells (see below) and the gut segment was clamped and harvested for fixation and analysis. The animal was then killed under anesthesia.

Three additional experiments were carried out to control for the possible effects of time and anesthesia on the distributions of perfusion and capillary transit time. These studies were identical to those described above, except that hypovolemia was not induced during the study of the second gut segment. Rather, fluid administration was continued throughout the study to preserve normovolemic conditions for both gut segments (time controls: first loop and second loop).

In summary, the study was designed to provide a comparison between high and low levels of gut blood flow in the presence of low or increased levels of systemic reflex vasoconstrictor tone. Because the blood volume measurements were only made during the low flow stages, determination of capillary transit time distributions were only available under low flow conditions (see below).

Measurements of regional blood flows and blood volumes. Spatial distributions of blood flow in the intestine segment were measured using $15 \mu \mathrm{m}$ polycarbonate microspheres (New England Nuclear, Boston, MA) labeled with ${ }^{103} \mathrm{Ru}$ and ${ }^{141} \mathrm{Ce}$. Microsphere suspensions were agitated with a vortex mixer for a minimum of $60 \mathrm{~s}$, and then immersed in an ultrasonic mixer for a minimum of $20 \mathrm{~min}$. To minimize the error in the flow measurements, the number of microspheres injected was sufficient to assure that more than 400 spheres would be trapped in a $100 \mathrm{mg}$ piece of tissue, even if the per gram blood flow to that piece was only $10 \%$ of the mean flow to the gut segment (8). Suspension volumes averaging $0.6 \mathrm{ml}$ were dispensed during intermittent agitation into a $1 \mathrm{ml}$ syringe fitted with a 25 gauge needle. The needle was inserted through the wall of a segment of latex tubing located just upstream from the luer hub connected to the narrower diameter PE cannula in the artery. During injection of microspheres, the syringe was held approximately horizontally and rotated axially to minimize settling of the microspheres in the syringe. Injections typically lasted for 2-4 min, and the tip of the needle was altered with respect to the blood flow direction during injection to minimize any streaming effects. Every injection was made by the same individual.

Blood volumes in each of the aliquots of the intestine wall were 
measured using autologous red blood cells labeled in vitro with ${ }^{99 \mathrm{~m}} \mathrm{Tc}$ using a stannous chloride method (9). In dog No. 1, labeled red cells were added to the entire systemic circulating pool of red cells, but this yielded an insufficient level of ${ }^{99 \mathrm{~m}} \mathrm{Tc}$ activity in the $100 \mathrm{mg}$ tissue pieces from the gut segment to accurately determine tissue blood volumes. Consequently, for the remainder of the experiments $(n=9)$ a mixture of labeled red cells and whole blood was used to perfuse the gut segment directly. Labeled red cells $(3 \mathrm{ml})$ were mixed with freshly sampled arterial blood $(17 \mathrm{ml})$ immediately before use in an effort to maintain a normal blood-gas composition in the mixture. The labeled red cell mixture was then used to supply inflow to the arterial pump for 2-3 min. While gut blood flow and inflow pressure were stable, the arterial and venous tubes then were simultaneously clamped. This immediately halted blood flow and trapped labeled cells in the tissue. Silk ligatures were tied around the mesenteric vessels to prevent retrograde loss of labeled blood when the cannulas were removed, and an aliquot of blood was obtained from the venous tubing for measurement of isotopic activity. The gut segment was then dissected free from the animal and immediately immersed in buffered glutaraldehyde $(7 \%)$ without permitting release of intravascular contents. Glutaraldehyde solution was injected into the gut lumen to hasten the fixation process.

Measurement of blood flow, blood volume, and capillary transit times. After fixation overnight, gut segments were trimmed of overlying fat, mesentery and superficial conducting vessels prior to sectioning, thereby excluding these areas from calculated blood flow or blood volume measurements. The gut wall was opened and washed with buffered saline, $\mathrm{pH} 7.4$, blotted dry, and weighed. Tissue was then sectioned into aliquots that were weighed and placed in numbered tubes for isotopic analysis in an automated gamma counter. The first 50 tissue pieces were intact through the intestine wall, contained mucosa and serosa, and weighed $\sim 100 \mathrm{mg}$. The next 150 pieces averaged $\sim 120 \mathrm{mg}$ and were split between mucosa and muscularis plus submucosa using a razor blade. The demarcation between mucosa and submucosa was visible at the edge of the tissue blocks. Histological analysis revealed that mucosal sections consistently contained only mucosa while muscularis sections consistently contained the submucosa as well as muscularis. The individual subsections were weighed and analyzed sequentially, permitting the calculation of blood flow partitioning between adjacent tissue regions. The remainder of the tissue was sectioned and placed in tubes so the entire injected isotopic activity could be calculated as the sum of counts from all tissue pieces.

Activity was assayed in each tissue piece for $60 \mathrm{~s}$ at photopeak energies coinciding with ${ }^{141} \mathrm{Ce}$ and ${ }^{103} \mathrm{Ru}$. Because ${ }^{99 \mathrm{~m}} \mathrm{Tc}$ and ${ }^{141} \mathrm{Ce}$ photopeak energies coincide, counting was repeated after allowing sufficient time for the decay of ${ }^{99 \mathrm{~m}} \mathrm{Tc}$ activity, which has a $6 \mathrm{~h} t_{1 / 2}$. The red blood cell ${ }^{99 \mathrm{~m}} \mathrm{Tc}$ activity was then determined as the difference between initial activity (representing ${ }^{141} \mathrm{Ce}$ plus ${ }^{99 \mathrm{~m}} \mathrm{Tc}$ ) minus the residual ${ }^{141} \mathrm{Ce}$ activity detected during the second counting. Counts in each tissue piece were corrected for the isotopic decay encountered during counting, and that encountered for ${ }^{141} \mathrm{Ce}$ between the first and second countings. The blood volume in each tissue piece was calculated by dividing its ${ }^{99 \mathrm{~m}} \mathrm{Tc}$ activity by the specific activity in blood sampled from the venous cannula. Comparison of ${ }^{99 \mathrm{~m}} \mathrm{Tc}$ activity in the venous and arterial cannulae in three experiments revealed close agreement and absence of systematic differences, suggesting that the infusion of labeled red cells was sufficient to establish equilibrium conditions. Blood flow in each tissue piece was determined as the product of the measured blood flow to the gut segment and the fraction of total ${ }^{141} \mathrm{Ce}$ or ${ }^{103} \mathrm{Ru}$ activity in the piece, and was normalized to the weight of the piece.

Capillary transit time in each piece of mucosa or serosa was determined as the ratio of capillary blood volume $(\mathrm{ml})$ to absolute blood flow $(\mathrm{ml} / \mathrm{min})$. The volume obtained from ${ }^{99 \mathrm{~m}} \mathrm{Tc}$ analysis represents total blood in capillaries and conducting vessels in each piece of tissue. To determine the fraction of that volume that was in the capillaries, 10 randomly selected blocks of tissue were embedded in paraffin, sectioned at $5 \mu \mathrm{m}$ thickness, stained, and mounted. Point counting was used to quantify total vascular volume density separately in mucosa (including crypts), submucosa and muscularis. In each region, 8,600 points were counted to achieve an accuracy of 5-8\% in each region (10). Vessels were classified as capillaries if $(a)$ no vascular smooth muscle was observed in the wall, and $(b)$ vessel diameter was less than $20 \mu \mathrm{m}$. Otherwise, they were classified as conducting vessels. The distribution of blood volume between conducting vessels and capillaries was assumed to be constant among tissue pieces in each gut loop. Therefore, capillary volume was calculated as the product of measured blood volume in each piece and the fraction of the vascular volume identified as within capillaries in that gut segment.

Analysis of blood flow, blood volume, and capillary transit time heterogeneity. Heterogeneity of blood flow among tissue pieces was analyzed separately in mucosa and muscularis/submucosa sections. To permit comparisons among experiments with differing per gram blood flows and tissue weights, the blood flow data were normalized in the following manner: First, fractional tissue weight was calculated for each piece by dividing its weight by the total gut segment weight. Next, the average blood flow over all tissue pieces was computed ( $\mathrm{ml} /$ $\mathrm{min} / \mathrm{kg}$ ), and the relative blood flow for each piece determined as the ratio of its flow $(\mathrm{ml} / \mathrm{min} / \mathrm{kg})$ divided by the average flow. This yielded a dimensionless measure of blood flow in each piece, expressed relative to an average flow of unity. Finally, a graphical frequency distribution was constructed for each gut region by summing the fractional weights of tissue pieces in bins according to their relative blood flows. Bin sizes were taken in intervals of 0.2 , and a total of $\sim 5,900$ tissue pieces were analyzed. This frequency distribution had a mean value of 1.0 and its dispersion indicated how different the blood flows were among tissue pieces, relative to the mean flow for that layer of the gut. Because the computed variables were dimensionless, multiple experiments could be combined to yield a description of the average response.

Recently, Humer et al. pointed out that nonlinear error is introduced if the dispersion of these distributions is calculated using the binned data (11). Accordingly, to quantify the heterogeneity of blood flow distributions in individual experiments we calculated the SD of each distribution using the individual dimensionless blood flows, incorporating a weighting of the values according to the mass of each piece. Relative dispersion was calculated as SD divided by the mean value of 1.0

A similar approach was used to represent graphically the frequency distributions of capillary blood volume and capillary transit time. For each tissue piece, a fractional weight was determined and capillary blood volume relative to the mean value for that layer was determined. A frequency histogram was then plotted by summing the fractional tissue weights of pieces in bins according to relative capillary blood volume. Likewise, transit times were calculated as the ratio of capillary blood volume to blood flow for each tissue piece. Graphical frequency distributions were then constructed by summing the fractional tissue weights of pieces in bins according to relative capillary transit time, in intervals of 0.2 . These graphs were constructed for each region of each gut segment, and summary plots were generated by summing the distributions across experiments. As with the blood flow distributions, calculated SDs of the blood volume and capillary transit time distributions were calculated from a weighted analysis of the individual tissue pieces rather than from the histograms themselves.

Measurements and calculations. Arterial, mixed venous, and gut venous blood samples were analyzed at $37^{\circ} \mathrm{C}$ for $\mathrm{pH}, \mathrm{PO}_{2}$, and $\mathrm{PCO}_{2}$ using standard blood-gas electrodes that were recalibrated hourly. Results were corrected to body temperature (12). Hemoglobinbound blood $\mathrm{O}_{2}$ contents were measured in duplicate by a cooximeter. Total blood $\mathrm{O}_{2}$ content was taken as the sum of dissolved and hemoglobin-bound components.

Gut blood flow was measured using an ultrasonic flow transducer whose accuracy was confirmed by comparison with a timed blood col- 


\begin{tabular}{|c|c|c|c|c|c|c|}
\hline & \multicolumn{3}{|c|}{ Normovolemic } & \multicolumn{3}{|c|}{ Hypovolemic } \\
\hline & Baseline & High flow & Low flow & Baseline & High flow & Low flow \\
\hline $\mathrm{QO}_{2}\left(\mathrm{ml} \cdot \mathrm{min}^{-1} \cdot \mathrm{kg}^{-1}\right)$ & $33.4 \pm 8.3$ & $27.7 \pm 9.9$ & $26.1 \pm 13.6$ & $9.3 \pm 3.0 *$ & $9.0 \pm 1.9 *$ & $7.8 \pm 1.4^{*}$ \\
\hline Cardiac output (Liters/min) & $4.38 \pm 0.69$ & $4.59 \pm 1.91$ & $4.76 \pm 2.36$ & $1.60 \pm 0.46^{*}$ & $1.56 \pm 0.27 *$ & $1.37 \pm 0.22 *$ \\
\hline $\mathrm{PaO}_{2}$ (Torr) & $84.8 \pm 13.3$ & $72.2 \pm 17.6$ & $82.8 \pm 13.9$ & $76.6 \pm 19.6$ & $76.3 \pm 18.8$ & $78.5 \pm 15.6^{*}$ \\
\hline $\mathrm{PaCO}_{2}$ (Torr) & $38.9 \pm 5.0$ & $37.6 \pm 7.4$ & $35.9 \pm 2.7$ & $36.2 \pm 5.6$ & $37.4 \pm 4.0$ & $38.4 \pm 2.2$ \\
\hline $\mathrm{pHa}$ & $7.371 \pm 0.054$ & $7.358 \pm 0.099$ & $7.359 \pm 0.074$ & $7.322 \pm 0.049 *$ & $7.324 \pm 0.088$ & $7.315 \pm 0.049$ \\
\hline $\mathrm{PvO}_{2}$ (Torr) & $51.6 \pm 4.1$ & $47.6 \pm 4.1$ & $44.8 \pm 1.9$ & $28.2 \pm 5.1 *$ & $28.0 \pm 4.7^{*}$ & $25.9 \pm 3.6^{*}$ \\
\hline $\mathrm{MAP}(\mathrm{mmHg})$ & $165 \pm 15$ & $159 \pm 20$ & $159 \pm 16$ & $122 \pm 31 *$ & $117 \pm 44 *$ & $89 \pm 32 *$ \\
\hline Ppw $(\mathrm{mmHg})$ & $9.2 \pm 1.6$ & $9.2 \pm 1.2$ & $9.8 \pm 2.3$ & $3.7 \pm 1.4^{*}$ & $4.0 \pm 2.1 *$ & $3.3 \pm 0.9 *$ \\
\hline Hemoglobin $(\mathrm{g} / \mathrm{dl})$ & $14.8 \pm 1.5$ & $12.3 \pm 2.1$ & $11.0 \pm 3.0$ & $12.5 \pm 3.9$ & $12.3 \pm 4.1$ & $12.3 \pm 4.1$ \\
\hline
\end{tabular}

Values are means $\pm 1 \mathrm{SD} .{ }^{*} P<0.05$ compared with corresponding normovolemic stage by paired $t$ test.

lection in a graduated cylinder. The blood flow signal was sampled digitally at $5 \mathrm{~Hz}$ for $60 \mathrm{~s}$, during which time blood samples were obtained.

Expired ventilation was directed through a mixing chamber where $\mathrm{O}_{2}$ and $\mathrm{CO}_{2}$ were sampled by gas analyzers whose calibrations were confirmed periodically using calibration gas standards. Exhaled minute ventilation was measured by a dry gas meter located proximal to the mixing chamber. Analog signals from the analyzers were digitized and used to calculate average systemic $\mathrm{VO}_{2}$ and $\mathrm{VCO}_{2}$ during each minute of the experiment. Whole body $\mathrm{VO}_{2}$ was corrected to STPD and normalized to body weight in kilogram. The $\mathrm{VO}_{2}$ for experimental stages was taken as an average over $3 \mathrm{~min}$, during which time the blood samples were obtained.

Cardiac output was calculated from the measured $\mathrm{VO}_{2}$ and the arterio-venous $\mathrm{O}_{2}$ content difference using the Fick equation. Systemic $\mathrm{O}_{2}$ delivery $\left(\mathrm{QO}_{2}\right)$ was calculated as the product of the arterial $\mathrm{O}_{2}$ content and cardiac output. Gut $\mathrm{QO}_{2}$ was calculated as the product of gut blood flow and arterial $\mathrm{O}_{2}$ content, and was normalized to gut wt. The $\mathrm{VO}_{2}$ for the intestinal segments was calculated as the product of gut blood flow and arteriovenous $\mathrm{O}_{2}$ content difference. The $\mathrm{O}_{2}$ extraction ratios for whole body and gut were calculated from blood $\mathrm{O}_{2}$ contents using mixed venous or gut venous oxygen contents $\left(\mathrm{ER}=\left(\mathrm{CaO}_{2}-\mathrm{CvO}_{2}\right) / \mathrm{CaO}_{2}\right)$.

Statistical methods. Comparisons between groups were made using analysis of variance and a two-tailed $t$ test for paired comparisons, as appropriate. Significance was determined at the $P<0.05$ level. Data are presented as mean \pm SD in the text and tables, and \pm SEM in the figures.

\section{Results}

Systemic $\mathrm{O}_{2}$ transport. In accordance with the experimental design, systemic $\mathrm{O}_{2}$ delivery, cardiac output, mean arterial pressure, pulmonary arterial pressure, and pulmonary capillary wedge pressure were maintained at high levels during the normovolemic stages of the experiment (Table I). This was associated with a relatively low systemic $\mathrm{O}_{2}$ extraction ratio and a normal systemic $\mathrm{O}_{2}$ uptake (Fig. 1). During hypovolemia, systemic $\mathrm{O}_{2}$ delivery decreased and the systemic $\mathrm{O}_{2}$ extraction ratio increased (Table I, $P<0.001$ ), but systemic $\mathrm{O}_{2}$ uptake was maintained indicating that $\mathrm{O}_{2}$ supply-independent conditions were preserved ( $P=$ NS, Fig. 1$)$. In control animals, systemic $\mathrm{O}_{2}$ delivery, cardiac output, arterial pressure, and pulmonary wedge pressures were maintained at high levels throughout the study (Table II and Fig. 1). Notably, a small but statistically evident decrease in arterial $\mathrm{PO}_{2}$ was noted at the low flow

stage in the experimental group during hypovolemia $(P<0.05)$. Also, in the control animals, there was a decrease in the systemic hemoglobin concentration between the first and second intestinal loop stages as a consequence of the intravenous fluid administration; this decrease was not seen in the experimental group because fluid administration was halted after the first gut loop was harvested.

Intestinal $\mathrm{O}_{2}$ transport. Oxygen delivery to the gut segment was controlled by adjusting the pump speed. These data are summarized in Table III. During high flow gut $\mathrm{O}_{2}$ delivery, gut $\mathrm{VO}_{2}$ and $\mathrm{O}_{2}$ extraction ratio were not different between normovolemic and hypovolemic stages. During the low flow stages of the experiment, gut $\mathrm{VO}_{2}$ was significantly reduced compared with the high flow conditions, indicating the existence of $\mathrm{O}_{2}$ supply-limited $\mathrm{VO}_{2}$ in the isolated gut. Moreover, during low flow a significantly higher gut $\mathrm{O}_{2}$ extraction ratio was reached during hypovolemia compared with normovolemia $(P<0.05)$, even though gut $\mathrm{QO}_{2}$ was not different between those conditions ( $P=$ NS, Table III). In the control ani-
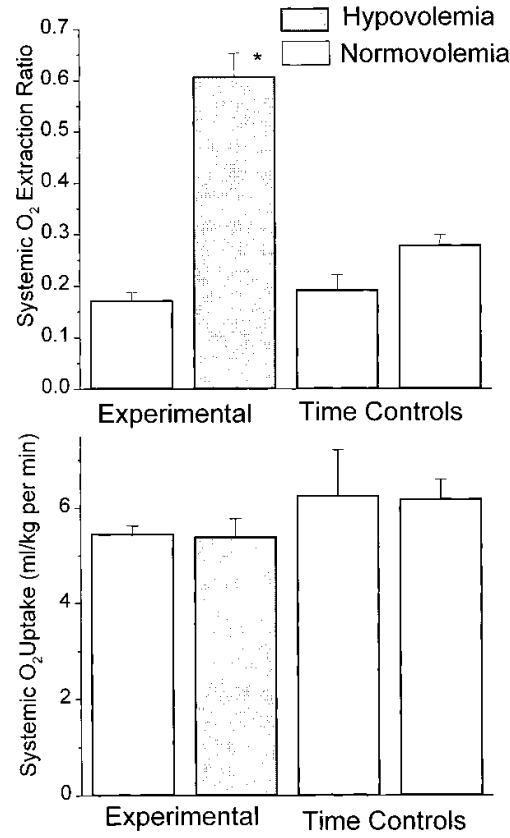

Figure 1. Systemic $\mathrm{O}_{2}$ extraction ratio (top) and systemic $\mathrm{O}_{2}$ uptake (bottom) during normovolemic and hypovolemic baseline stages (Experimental) and at baseline stages for the first and second gut loop (Time Controls). Systemic $\mathrm{O}_{2}$ extraction ratio was significantly increased during hypovolemia $(P<0.05)$ Error bars represent SEM. 
Table II. Systemic Blood Gas and Hemodynamics Summary Time Controls

\begin{tabular}{|c|c|c|c|c|c|c|}
\hline & \multicolumn{3}{|c|}{ First loop } & \multicolumn{3}{|c|}{ Second loop } \\
\hline & Baseline & High flow & Low flow & Baseline & High flow & Low flow \\
\hline $\mathrm{QO}_{2}\left(\mathrm{ml} \cdot \mathrm{min}^{-1} \cdot \mathrm{kg}^{-1}\right)$ & $33.8 \pm 10.0$ & $34.7 \pm 12.7$ & $29.7 \pm 7.8$ & $22.3 \pm 2.7$ & $28.1 \pm 11.7$ & $23.5 \pm 7.3$ \\
\hline Cardiac output (Liters/min) & $3.54 \pm 1.09$ & $3.77 \pm 1.63$ & $3.29 \pm 1.15$ & $3.08 \pm 0.75$ & $4.39 \pm 1.93$ & $4.39 \pm 1.48$ \\
\hline $\mathrm{PaO}_{2}$ (Torr) & $94.8 \pm 7.7$ & $97.4 \pm 4.9$ & $103.8 \pm 18.4$ & $94.5 \pm 4.0$ & $64.0 \pm 46.9$ & $91.9 \pm 5.3$ \\
\hline $\mathrm{PaCO}_{2}$ (Torr) & $35.6 \pm 3.3$ & $33.2 \pm 0.8$ & $32.5 \pm 2.3$ & $33.2 \pm 1.0$ & $34.0 \pm 0.6$ & $34.2 \pm 0.5$ \\
\hline $\mathrm{pHa}$ & $7.319 \pm 0.096$ & $7.364 \pm 0.099$ & $7.336 \pm 0.077$ & $7.319 \pm 0.099$ & $7.311 \pm 0.092$ & $7.296 \pm 0.128$ \\
\hline $\mathrm{PvO}_{2}$ (Torr) & $52.2 \pm 7.1$ & $50.7 \pm 5.8$ & $49.6 \pm 3.5$ & $43.7 \pm 2.6$ & $46.6 \pm 7.6$ & $44.9 \pm 6.4$ \\
\hline MAP (mmHg) & $152 \pm 29$ & $154 \pm 17$ & $155 \pm 11$ & $151 \pm 5$ & $152 \pm 6$ & $147 \pm 14$ \\
\hline Ppw $(\mathrm{mmHg})$ & $12.3 \pm 4.9$ & $12.7 \pm 5.5$ & $11.7 \pm 5.5$ & $11.7 \pm 5.5$ & $12.3 \pm 4.9$ & $13.7 \pm 4.0$ \\
\hline Hemoglobin $(\mathrm{g} / \mathrm{dl})$ & $17.1 \pm 1.4$ & $16.6 \pm 1.2$ & $16.3 \pm 1.2$ & $13.1 \pm 0.5^{*}$ & $11.7 \pm 1.6^{*}$ & $9.8 \pm 2.1^{*}$ \\
\hline
\end{tabular}

Values are means \pm 1 SD. $* P<0.05$ compared with corresponding Loop 1 stage by paired $t$ test.

mals, gut $\mathrm{VO}_{2}$ was decreased during low flow conditions in both the first and second gut loops, also indicating $\mathrm{O}_{2}$ supplylimited conditions (Table IV). However, there was no difference in $\mathrm{O}_{2}$ extraction ratio between the first and second gut segments at the low flow stage.

Regional perfusion in the gut. Table V summarizes the effects of hypovolemia on regional intestinal blood flows in $\mathrm{mu}-$ cosa and muscularis under low flow and high flow conditions. For each gut loop a mean per gram blood flow was calculated for mucosa and muscularis regions by averaging the flows obtained among tissue pieces. Those mean values were then averaged across experiments to yield the overall mean blood flows (expressed as $\mathrm{ml} / \mathrm{min} / \mathrm{gram}$ ) shown in Table V. During high flow, systemic hypovolemia produced a significant decrease in absolute smooth muscle blood flow $(P<0.003)$ while average mucosal blood flow tended to increase $(P=\mathrm{NS})$. Likewise, during low flow conditions hypovolemia caused a significant decrease in muscularis flow $(P<0.003)$ while flow in mucosal tissue tended to increase $(P=\mathrm{NS})$.

Distribution of blood flow between mucosa and muscularis. Partitioning of blood flow between mucosa and smooth muscle was determined from the split tissue sections by comparing the average per gram blood flows in the two regions under the different experimental conditions. During normovolemia, blood flow to mucosa averaged $42.9 \pm 8.8 \%$ of gut perfusion at high flow, (Fig. 2, top) versus $39.5 \pm 12.7 \%$ under low flow conditions ( $P=$ NS; Fig. 2, bottom $)$. During hypo- volemia, blood flow was significantly redistributed toward the mucosa $(P=0.003)$, and averaged $66.3 \pm 14.3 \%$ under high flow (Fig. 2, top) and 62.5 $\pm 7.6 \%$ during low flow (Fig. 2, bottom) conditions. Thus, stimulation of reflex vasoconstriction caused a redistribution of blood flow toward mucosa and away from muscularis, whereas changes in blood flow without a change in vasoconstrictor tone did not produce any redistribution between the two compartments. In control experiments where normovolemia was maintained there was no redistribution of flow toward mucosa over time (Fig. 3).

Heterogeneity of blood flow within layers of the gut wall. Fig. 4 (top) summarizes the effects of hypovolemia on the heterogeneity of perfusion among tissue pieces in gut muscularis under low flow conditions. The plot represents a frequency distribution showing the mass of tissue perfused at different flow rates. Plots for individual gut segments were generated by summing the fractional weights of smooth muscle pieces into bins according to their blood flows relative to the mean muscularis flow. The summary plot in Fig. 4 (top) was then generated by summing the individual bin contents across all experiments $(n=7)$. Blood flows are represented relative to the mean, where a value of 1.0 represents the average muscularis flow and the dispersion around that value reflects the spatial heterogeneity of perfusion. Distributions show that most of the smooth muscle pieces had blood flows close to the average value, although significant differences from this mean value were detected among pieces. For example, some smooth mus-

Table III. Intestinal Blood Gas and Hemodynamics Summary

\begin{tabular}{|c|c|c|c|c|c|c|}
\hline & \multicolumn{3}{|c|}{ Normovolemic } & \multicolumn{3}{|c|}{ Hypovolemic } \\
\hline & Baseline & High flow & Low flow & Baseline & High flow & Low flow \\
\hline Gut $\mathrm{QO}_{2}\left(\mathrm{ml} \cdot \mathrm{min}^{-1} \cdot \mathrm{kg}^{-1}\right)$ & $87.7 \pm 28.7$ & $77.7 \pm 31.1$ & $29.8 \pm 10.0$ & $45.7 \pm 19.0 *$ & $61.1 \pm 24.8$ & $25.6 \pm 9.8$ \\
\hline Gut $\mathrm{VO}_{2}\left(\mathrm{ml} \cdot \mathrm{min}^{-1} \cdot \mathrm{kg}^{-1}\right)$ & $18.7 \pm 4.9$ & $18.0 \pm 4.0$ & $13.1 \pm 4.1$ & $20.3 \pm 6.5$ & $19.9 \pm 5.3$ & $14.4 \pm 5.0$ \\
\hline Gut $\mathrm{QO}_{2}$ extraction ratio & $0.23 \pm 0.08$ & $0.26 \pm 0.10$ & $0.45 \pm 0.06$ & $0.50 \pm 0.17 *$ & $0.37 \pm 0.14$ & $0.60 \pm 0.14 *$ \\
\hline Gut blood flow $\left(\mathrm{ml} \cdot \mathrm{min}^{-1} \cdot \mathrm{kg}^{-1}\right)$ & $469.6 \pm 186.6$ & $492.8 \pm 176.1$ & $185.0 \pm 14.8$ & $277.5 \pm 56.3^{*}$ & $386.4 \pm 78.5$ & $160.2 \pm 55.0$ \\
\hline Gut venous PO2 (Torr) & $46.1 \pm 7.5$ & $43.4 \pm 6.7$ & $35.3 \pm 1.6$ & $32.2 \pm 8.4^{*}$ & $38.0 \pm 8.0$ & $29.7 \pm 6.6$ \\
\hline Vascular resistance $\left(\mathrm{mmHg} \cdot \mathrm{min} \cdot \mathrm{kg} \cdot \mathrm{ml}^{-1}\right)$ & $0.374 \pm 0.112$ & $0.303 \pm 0.089$ & $0.379 \pm 0.194$ & $0.413 \pm 0.209$ & $0.345 \pm 0.174$ & $0.675 \pm 0.378$ \\
\hline Gut arterial pressure (mmHg) & $160 \pm 16$ & $141 \pm 29$ & $70 \pm 33$ & $106 \pm 20^{*}$ & $124 \pm 31$ & $103 \pm 46$ \\
\hline
\end{tabular}

Values are means $\pm \mathrm{SD} .{ }^{*} P<0.05$ compared with corresponding normovolemic stage by paired $t$ test. 


\begin{tabular}{|c|c|c|c|c|c|c|}
\hline & \multicolumn{3}{|c|}{ First loop } & \multicolumn{3}{|c|}{ Second loop } \\
\hline & Baseline & High flow & Low flow & Baseline & High flow & Low flow \\
\hline Gut $\mathrm{QO}_{2}\left(\mathrm{ml} \cdot \mathrm{min}^{-1} \cdot \mathrm{kg}^{-1}\right)$ & $102.1 \pm 37.3$ & $100.4 \pm 27.5$ & $33.9 \pm 6.2$ & $77.1 \pm 16.3$ & $86.2 \pm 28.4$ & $25.1 \pm 8.9$ \\
\hline Gut $\mathrm{VO}_{2}\left(\mathrm{ml} \cdot \mathrm{min}^{-1} \cdot \mathrm{kg}^{-1}\right)$ & $18.3 \pm 2.3$ & $18.0 \pm 2.2$ & $13.2 \pm 1.0$ & $20.6 \pm 5.8$ & $21.0 \pm 7.3$ & $11.0 \pm 4.7$ \\
\hline Gut $\mathrm{O} 2$ extraction ratio & $0.19 \pm 0.05$ & $0.19 \pm 0.05$ & $0.40 \pm 0.08$ & $0.26 \pm 0.02 *$ & $0.24 \pm 0.02$ & $0.43 \pm 0.03$ \\
\hline Gut blood flow $\left(\mathrm{ml} \cdot \mathrm{min}^{-1} \cdot \mathrm{kg}^{-1}\right)$ & $383.1 \pm 66.9$ & $388.9 \pm 39.4$ & $135.6 \pm 19.1$ & $400.0 \pm 73.3$ & $492.9 \pm 25.5$ & $170.7 \pm 9.8$ \\
\hline Gut venous $\mathrm{PO}_{2}$ (Torr) & $52.1 \pm 7.5$ & $49.8 \pm 4.8$ & $38.5 \pm 3.9$ & $44.1 \pm 2.1$ & $43.5 \pm 3.0$ & $38.0 \pm 3.4$ \\
\hline Vascular resistance $\left(\mathrm{mmHg} \cdot \mathrm{min} \cdot \mathrm{kg} \cdot \mathrm{ml}^{-1}\right)$ & $0.364 \pm 0.098$ & $0.396 \pm 0.073$ & $0.404 \pm 0.061$ & $0.364 \pm 0.042$ & $0.270 \pm 0.081$ & $0.267 \pm 0.029$ \\
\hline Gut arterial pressure (mmHg) & $157 \pm 32$ & $173 \pm 3$ & $63 \pm 18$ & $155 \pm 10$ & $143 \pm 40$ & $49 \pm 4$ \\
\hline
\end{tabular}

Values are means \pm 1 SD. ${ }^{*} P<0.05$ compared with corresponding Loop 1 stage by paired $t$ test.

cle regions had blood flows that were $\sim 20 \%$ of the average flow, while other regions received blood flows that were two to four times the mean flow. The SD of the perfusion distribution was calculated in each experiment to provide an index of blood flow heterogeneity. As shown in Table VI, hypovolemia produced a significant increase in the SD of smooth muscle blood flow distributions under high and low flow conditions. By contrast, blood flow itself had no significant effect on the spatial dispersion of blood flow in smooth muscle.

For mucosa, the heterogeneity of blood flows among tissue pieces is summarized in Fig. 5 (top). As before, a relative blood flow of 1.0 represents a per gram blood flow equal to the mean mucosal blood flow at that stage. Like muscularis, mucosa showed a significant degree of blood flow heterogeneity. Addition of reflex vasoconstrictor tone with hypovolemia significantly increased this heterogeneity at high $(P<0.01)$ but not low flow conditions (Table VI). Changes in blood flow had no significant effect on the dispersion of blood flow in mucosa, under either normovolemic or hypovolemic stages $(P=\mathrm{NS})$.

In control experiments, the blood flow heterogeneity in mucosa and muscularis were similar in magnitude to that seen in the experimental groups (Table VI). Time alone tended to decrease heterogeneity in mucosa at high flow, but no significant effects were detected.

Tissue capillary blood volumes and transit times. Measurements of tissue blood volume were only made during the low flow stage for each gut segment. Capillary volumes (as percent of total microvascular volume) were not identical in the different layers of the gut wall. In mucosa, $75.3 \pm 10.2 \%$ of the blood

Table V. Effects of Systemic Hypovolemia on Absolute Blood Flows to Mucosa and Muscularis

\begin{tabular}{llll}
\hline & Normovolemic & & Hypovolemic \\
\hline Mucosa & & & \\
High flow & $0.57 \pm 0.27$ & NS & $0.75 \pm 0.36$ \\
Low flow & $0.19 \pm 0.11$ & NS & $0.25 \pm 0.09$ \\
Smooth muscle & & & \\
High flow & $0.79 \pm 0.22^{*}$ & & $0.38 \pm 0.18$ \\
Low flow & $0.27 \pm 0.05^{*}$ & & $0.14 \pm 0.02$ \\
& & & \\
\hline
\end{tabular}

Blood flows are expressed as $\mathrm{ml} / \mathrm{min}$ per gram of tissue weight. Values are means \pm SD. * Signifies $P<0.01$. volume resided in the capillaries during normovolemia, compared with $90.0 \pm 5.4 \%$ during hypovolemia $(P=0.01)$. Thus, most of the vessels in mucosa were classified as capillaries, and nearly all of the blood volume resided in capillaries during hypovolemia. In smooth muscle, capillary blood volume represented $44.9 \pm 7.8 \%$ of the tissue blood volume during normovolemia, compared with $65.5 \pm 5.5 \%$ during hypovolemia $(P=$ $0.01)$. Thus, hypovolemia tended to reduce the relative volume of the conducting vessels within the smooth muscle, causing a greater proportion of the blood volume to be found in capillaries. The distribution of capillary blood volumes among pieces of muscularis is depicted in Fig. 4 (middle), where again a value of 1.0 corresponds to the average smooth muscle capillary blood volume. Under normovolemic conditions a relatively broad distribution was found, with some pieces having capillary blood volumes of less than half of the mean while others had more than twice the mean value. During the hypovolemic stage, reflex increases in vascular tone caused a narrowing of this distribution in smooth muscle $(P=0.01)$. Fig. 5 (middle) depicts the heterogeneity of capillary blood volumes among aliquots of mucosa. Heterogeneity within mucosa was similar in magnitude to that seen in smooth muscle. Systemic hypovolemia tended to narrow the dispersion of this distribution, but this effect was not statistically significant.

Fig. 4 (bottom) shows the effect of systemic hypovolemia on the heterogeneity of capillary transit times in gut smooth muscle under low flow conditions $(n=6)$. Of course, such dis-

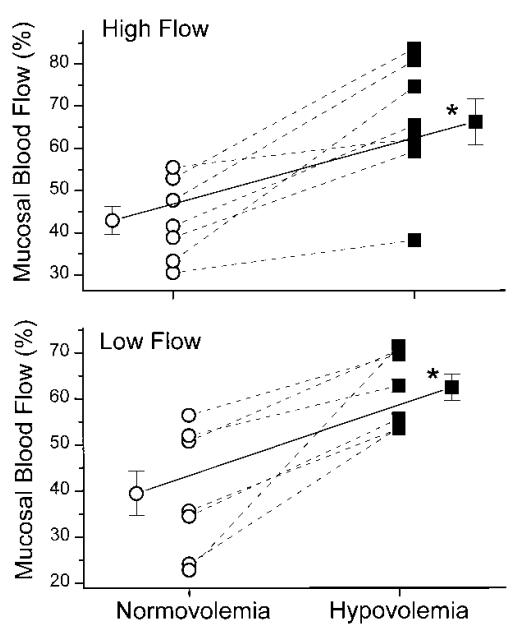

Figure 2. Effects of normovolemia and hypovolemia on the fractional distribution of blood flow between intestinal mucosa and muscularis/submucosa under High Flow (top) and Low Flow (bottom) conditions $(n=7)$. The fraction of intestinal blood flow distributed to mucosa increased significantly during hypovolemia at both levels of blood flow. Error bars represent SEM. $* P<0.01$. 

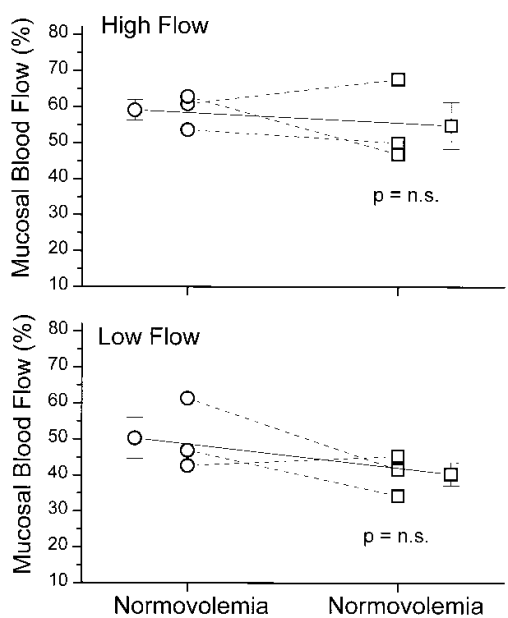

tributions depend on the assumptions (a) that capillaries visualized during point counting all had flow in them, and $(b)$ that the fraction of blood volume in capillaries versus conducting vessels determined from morphologic analysis in a small number of tissue blocks applies in unrestricted fashion to every piece. Once again, a relative transit time of 1.0 represents the

Smooth Muscle - Low Flow Blood Flow Heterogeneity

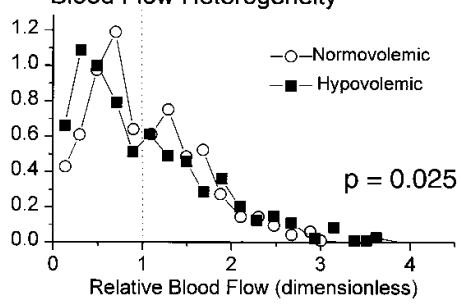

Blood Volume Heterogeneity
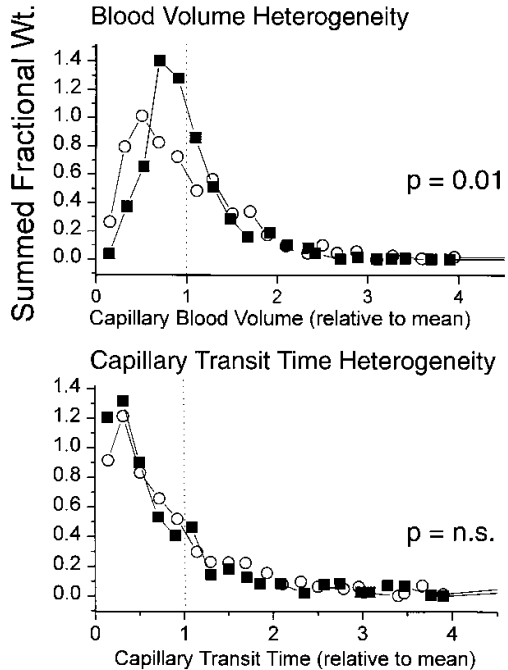

Figure 4. Frequency distributions showing the effects of hypovolemia on heterogeneity of blood flow (top), heterogeneity of blood volume (middle), and heterogeneity of capillary transit times (bottom) in intestinal smooth muscle. In each case, an abscissa value of 1.0 represents the mean value for the smooth muscle. Plots represent the cumulative distributions from all experiments; the width of the distribution is a measure of the heterogeneity. In smooth muscle, hypovolemia elicited an increase in the dispersion of muscularis blood flow and a simultaneous decrease in the dispersion of capillary blood volumes among tissue pieces. The dispersion of capillary transit times, calculated from the ratio of capillary volume to flow in each piece, therefore was preserved.
Table VIa. Effects of Flow and Hypovolemia on Spatial Heterogeneity of Blood Flow

\begin{tabular}{llll}
\hline & Normovolemic & & Hypovolemic \\
\hline Mucosa & & & \\
High flow & $0.517 \pm 0.064$ & $P<0.01$ & $0.774 \pm 0.067$ \\
Low flow & $0.777 \pm 0.083$ & $P=\mathrm{NS}$ & $0.716 \pm 0.045$ \\
Smooth muscle & & & \\
High flow & $0.585 \pm 0.067$ & $P=0.016$ & $0.728 \pm 0.059$ \\
Low flow & $0.592 \pm 0.050$ & $P=0.025$ & $0.767 \pm 0.037$ \\
& & & \\
\hline
\end{tabular}

Table VIb. Control Experiments Effects of Flow and Time on Spatial Heterogeneity of Blood Flow (Normovolemia Maintained)

\begin{tabular}{|c|c|c|c|}
\hline & First loop & & Second loop \\
\hline \multicolumn{4}{|l|}{ Mucosa } \\
\hline High flow & $0.613 \pm 0.049$ & $P=0.08$ & $0.463 \pm 0.019$ \\
\hline Low flow & $0.603 \pm 0.011$ & $P=\mathrm{NS}$ & $0.558 \pm 0.047$ \\
\hline \multicolumn{4}{|c|}{ Smooth muscle } \\
\hline High flow & $0.619 \pm 0.109$ & $P=\mathrm{NS}$ & $0.620 \pm 0.036$ \\
\hline Low flow & $0.570 \pm 0.80$ & $P=\mathrm{NS}$ & $0.734 \pm 0.101$ \\
\hline
\end{tabular}

average mucosal capillary transit time at that stage. As with the blood flow distributions, a significant amount of dispersion around the mean capillary transit time was detected among tissue pieces. Interestingly, the changes in capillary volume heterogeneity caused by hypovolemia (Fig. 4, middle) were closely matched to the changes in regional blood flow heterogeneity (Fig. 4, top) such that the distribution of capillary transit times were unchanged with hypovolemia in the smooth muscle. Fig. 5 (bottom) depicts the dispersion of capillary transit times among mucosal aliquots. In mucosa, systemic hypovolemia did not significantly alter either the flow heterogeneity (Fig. 5, top) or the capillary volume heterogeneity (Fig. 5, middle). Thus, although significant heterogeneity of capillary transit times existed in both muscularis and mucosa, addition of neurohumoral vasoconstrictor tone did not change the extent of this dispersion (Table VII).

Given that no change in the heterogeneity of capillary transit times was detected, we subsequently carried out a power analysis to determine our ability to detect a small change in the face of experimental measurement error. Based on the paired differences in transit time heterogeneity between normovolemic and hypovolemic stages analysis, the power to detect a $50 \%$ change was $72 \%$ in smooth muscle and $56 \%$ in mucosa. In both regions, the $95 \%$ confidence interval for the mean change in heterogeneity overlapped zero change.

\section{Discussion}

Rationale and summary. When cardiac output is decreased, reflex neurohumoral vasoconstriction helps to maintain blood pressure and redistributes $\mathrm{O}_{2}$ supply away from organs with lesser oxygen demands. According to the metabolic theory of microvascular control, local metabolic vasodilation competes with this vasoconstriction, thereby preserving $\mathrm{O}_{2}$ supply to re- 

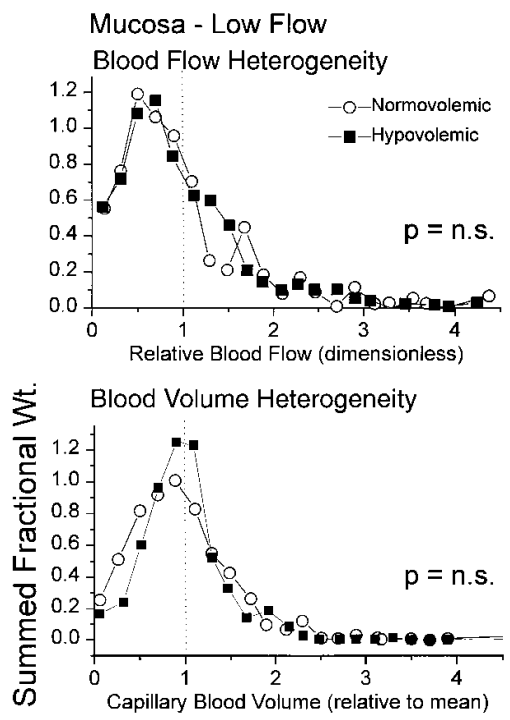

Capillary Transit Time Heterogeneity

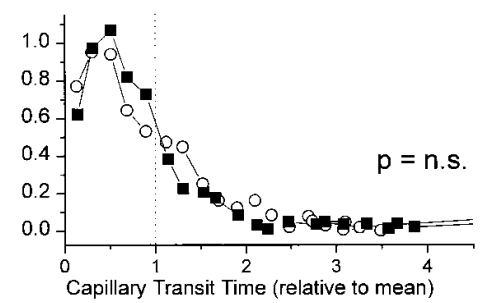

Figure 5. Frequency distributions showing the effects of hypovolemia on heterogeneity of blood flow (top), heterogeneity of blood volume (middle), and heterogeneity of capillary transit times (bottom) in intestinal mucosa. In each case, an abscissa value of 1.0 represents the mean value for the mucosa. Plots represent the cumulative distributions from all experiments. In mucosa, hypovolemia did not significantly alter the dispersion of blood flow, nor did it significantly affect the dispersion of capillary blood volumes among tissue pieces. Therefore, capillary transit time heterogeneity did not change with hypovolemia.

gions with high metabolic needs (3-5). Vasoconstriction also contributes to the increases in $\mathrm{O}_{2}$ extraction seen locally within tissues, presumably by limiting blood flow in areas with lesser metabolic need. In this regard, we previously found that the local critical $\mathrm{O}_{2}$ extraction ratio in isolated pump-perfused intestine was high $(69 \pm 3 \%)$ when the animals had been hemorrhaged to enhance reflex vasoconstriction. By contrast, local gut critical extractions were significantly impaired $(45 \pm 11 \%)$

Table VIIa. Effect of Hypovolemia on Spatial Heterogeneity of Capillary Transit Times

\begin{tabular}{ccc}
\hline \multicolumn{1}{c}{ Normovolemia } & & Hypovolemia \\
\hline $\begin{array}{c}\text { Mucosa } \\
1.092 \pm 0.153\end{array}$ & $P=\mathrm{NS}$ & $1.288 \pm 0.374$ \\
$\begin{array}{c}\text { Smooth muscle } \\
1.118 \pm 0.130\end{array}$ & $P=\mathrm{NS}$ & $1.501 \pm 0.254$ \\
\hline
\end{tabular}

Table VIIb. Control Experiments Effect of Time on Spatial Heterogeneity of Capillary Transit Times (Normovolemia Maintained)

\begin{tabular}{ccc}
\hline First loop & & Second loop \\
\hline Mucosa & $P=\mathrm{NS}$ & $1.5318 \pm 0.3167$ \\
$1.19573 \pm 0.259$ & & \\
$\begin{array}{c}\text { Smooth muscle } \\
1.11521 \pm 0.135\end{array}$ & $P=\mathrm{NS}$ & $1.17493 \pm 0.0787$ \\
\hline
\end{tabular}

when reflex vasoconstriction was limited by administering intravenous fluids to keep the animals systemically normovolemic (6). Similar results were obtained in isolated perfused hindlimb (7), indicating that the response is not limited to intestine. However, the microvascular adjustments responsible for the improvement in $\mathrm{O}_{2}$ extraction efficacy during hypovolemia were not known. The present study was designed to test whether hypovolemia-induced vasoconstriction $(a)$ alters the spatial dispersion of blood flow heterogeneity in gut mucosa or muscularis, $(b)$ alters the distribution of capillary transit times in mucosa or muscularis, or $(c)$ causes a redistribution of blood flow between mucosa and muscularis.

Our data show that significant spatial heterogeneity of blood flow normally exists within the gut wall. In mucosa, blood flow in some tissue pieces was $<20 \%$ of the mean while other regions had more than three times the average mucosal flow. Heterogeneity of similar magnitude was found among aliquots of muscularis. When the animals were bled to augment vasoconstrictor tone, the spatial heterogeneity of blood flow in muscularis increased significantly. By itself, this might suggest that vasoconstriction should interfere with tissue gas exchange in that region. However, hypovolemia simultaneously narrowed the heterogeneity of capillary blood volume distributions. Because capillary transit time is the ratio of capillary volume to flow, there was no net effect on the dispersion of capillary transit times around the mean value. These results suggest that part of the improved tissue ability to extract oxygen during systemic hypovolemia may be due to the salutary effects of neurohumoral vasoconstriction on the regulation of both capillary blood flow and volume, so that capillary transit times are matched to local metabolic need.

In mucosa, increases in vasoconstrictor tone increased the spatial heterogeneity of blood flow under high flow, but not under low flow conditions. By contrast, in control experiments the mucosal heterogeneity tended to decrease over the same time period. Unfortunately, our experimental design did not permit measurements of transit time dispersion during high flow. However, we would predict that physiological regulation would be less efficient under those conditions because neurohumoral vasoconstriction (elicited by hypovolemia) would not be balanced by local metabolic vasodilation (due to the excess oxygen supply relative to $\mathrm{O}_{2}$ demand). When the delivery of $\mathrm{O}_{2}$ to a tissue is abundant relative to its $\mathrm{O}_{2}$ demand, heterogeneity of perfusion is less important because even poorly perfused regions may receive an adequate $\mathrm{O}_{2}$ supply. By contrast, when the $\mathrm{O}_{2}$ delivery to the tissue is reduced, appropriate vascular regulation of $\mathrm{O}_{2}$ delivery is required to supply adequate capillary perfusion while preventing excessive perfusion of areas with low metabolic need. In the gut, the metabolic vasodilatory response (i.e., reactive hyperemia) is more vigorous in mucosa than in muscularis (13). Thus under high flow conditions, metabolic vasodilation in mucosa is minimal and unnecessary for the adequate distribution of $\mathrm{O}_{2}$. Under low flow conditions, overall blood flow to the gut wall is diminished (Table V) and the addition of neurohumoral vasoconstriction causes microvascular redistribution of perfusion that improves oxygen extraction without altering heterogeneity of capillary transit times.

Reflex vasoconstriction had a marked effect on the partitioning of blood flow between mucosa and muscularis regions of the gut wall. In this regard, systemic hypovolemia produced an increase in the fraction of gut flow distributed to mucosa in 
every gut loop studied, regardless of whether the segments were perfused at high flow (i.e., under $\mathrm{O}_{2}$ supply-independent conditions), or low flow (i.e., $\mathrm{O}_{2}$ supply-dependent) conditions. In human tissue, Hultén et al. found that electrical stimulation of perivascular nerves led to a vasoconstriction that was more intense in muscularis than mucosa, which caused a redistribution of blood flow toward the latter region (14). However, the same study failed to find evidence of an intramural redistribution in feline tissue. In our study, blood flow $(\mathrm{ml} /$ $\mathrm{min} / \mathrm{gram}$ ) to muscularis decreased during hypovolemic vasoconstriction, while flow to mucosa tended to increase. Intestinal mucosa exhibits a high metabolic rate compared with muscularis (15), has capillaries with greater permeability to macromolecules (16), and exhibits greater tissue $\mathrm{O}_{2}$ extraction than serosa based on microelectrode comparisons of surface $\mathrm{PO}_{2}$ (17). By redistributing blood flow away from muscularis toward mucosa, reflex vasoconstriction may enhance local tissue $\mathrm{O}_{2}$ extraction by lessening the distribution of blood flow to muscularis and thereby preserving $\mathrm{O}_{2}$ supply for the greater metabolic demands of the mucosa. We therefore conclude that the most likely mechanism to explain the improvement in gut $\mathrm{O}_{2}$ extraction during hypovolemia is a redistribution of blood flow toward mucosa which results from a selective vasoconstriction in the muscularis and submucosa.

This conclusion is further supported by a post hoc correlation analysis of the $\mathrm{O}_{2}$ extraction responses and the blood flow redistribution data among individual animals. Consistent with our previous study (6), gut $\mathrm{O}_{2}$ extraction under $\mathrm{O}_{2}$ supplydependent conditions was better during hypovolemia than normovolemia. This was evidenced by the higher gut $\mathrm{O}_{2}$ extractions seen under low flow conditions during hypovolemia $(59.7 \%)$ compared with normovolemia $(44.7 \%)$ at the same gut $\mathrm{O}_{2}$ delivery (Table III). When the changes in percent $\mathrm{O}_{2}$ extraction (low flow, normovolemia versus hypovolemia) were plotted against the changes in percent blood flow to mucosa (Fig. 3, low flow, normovolemia versus hypovolemia), a significant correlation was found $(r=0.82$, slope: 0.90 , intercept: $-3.6, P=0.022$ ). Thus, the animals exhibiting the greatest increases in supply-limited $\mathrm{O}_{2}$ extraction during hypovolemia were those that showed the greatest redistribution toward mucosa and away from muscularis/submucosa.

Comparison to previous work. While our data suggest that reflex neurohumoral vasoconstriction enhances the efficacy of $\mathrm{O}_{2}$ extraction in small intestine, Shepherd (18) found that electrical stimulation of perivascular nerves caused $\mathrm{O}_{2}$ extraction and use to decrease in canine small bowel. Lautt and Graham also found that electrical nerve stimulation increased vascular resistance while decreasing $\mathrm{VO}_{2}$ in feline intestine (19). Our previous study was motivated by a preliminary observation that autoperfused gut segments consistently reached high critical $\mathrm{O}_{2}$ extraction ratios if the animals had been bled to elicit increases in reflex vasomotor tone. By contrast, if the animals were kept in a normovolemic state while local gut $\mathrm{O}_{2}$ delivery was lowered by reducing pump speed, consistently poor critical gut $\mathrm{O}_{2}$ extraction ratios were observed. Our previous study also showed that supply-limited $\mathrm{VO}_{2}$ in a pump-perfused preparation could be increased at constant $\mathrm{O}_{2}$ delivery by hemorrhaging an animal that had been previously kept normovolemic. Therefore, the differences in $\mathrm{O}_{2}$ extraction efficacy could not be attributed to the use of pump versus autoperfusion. A major difference between previous studies and ours relates to the use of electrical nerve stimulation, as opposed to intrinsic reflex neurohumoral vasoconstriction. Perhaps by acting exclusively on larger flow controlling arteries, electrical nerve stimulation may increase resistance without improving the microvascular distribution. In support of this notion, Hultén et al. (14) found that electrical nerve stimulation significantly increased vascular resistance in feline intestine, but failed to alter significantly the distribution of flow between mucosa and muscularis. By acting on vessels responsible for microvascular distribution, neurohumoral vasoconstriction may enhance $\mathrm{O}_{2}$ extraction by achieving a more effective distribution of microvascular flow. In this regard, both vasopressin and renin contribute to the increases in intestinal vasoconstriction caused by hemorrhage in cats (20). Moreover, Dodd et al. found that denervation of canine intestine did not impair the increases in gut $\mathrm{O}_{2}$ extraction seen during systemic hypoxemia, nor did it ablate the chemoreflex vasoconstriction seen in the isolated gut (21). Collectively, these results suggest that the vascular effects of electrically stimulating the perivascular nerves in intestine are not equivalent to those produced by stimulating neurohumoral vasoconstriction via hypovolemia.

In this regard, it is interesting to note that vascular resistance in the gut segment was not significantly increased during hypovolemia in our study. An ability of reflex vasoconstriction to redistribute blood flow within and between mucosa and muscularis without significantly increasing vascular resistance confirms the important functional distinction between flowcontrolling vessels responsible for the bulk of vascular resistance and the distribution vessels responsible for microvascular regulation.

Heterogeneity of tissue blood flow. The existence of spatial heterogeneity of regional blood flow has long been recognized in the lung (22), heart (23-25), and skeletal muscle (2629), and the significance of transit time heterogeneity for tissue gas exchange is widely known (30). Using radioactive microspheres, Bassingthwaighte et al. found relative dispersions (SD/mean) ranging from 16 to $47 \%$ in heart muscle (31). By comparison, our data revealed relative dispersions ranging from 44 to $97 \%$ in muscularis and from 23 to $97 \%$ in mucosa. When microspheres are used to measure heterogeneity, the relative dispersion detected depends on the size of the tissue samples (31). With larger sizes, spatial variations in flow within the tissue piece cannot be detected and the degree of heterogeneity is underestimated. Conversely, if excessively small pieces of tissue are taken, statistical errors are encountered because the number of microspheres per piece is insufficient to accurately represent the flow distribution. In our study, sufficient numbers of microspheres were injected to limit such error in tissue samples that averaged $\sim 100 \mathrm{mg}$ in each of our experiments. Tissue samples of $100 \mathrm{mg}$ size represents a degree of definition that was 10-fold finer than used by Marcus et al. in dog heart (32) and twofold finer than used by Bassingthwaighte et al. (31). While it is possible that the greater degree of heterogeneity we observed in the gut could be explained by the use of smaller pieces, intestine and heart may have inherently different degrees of heterogeneity in regional blood flows. Allard et al. compared red blood cell transit time distributions in rabbit heart endocardium and epicardium (33). While they found no differences in the degree of heterogeneity between these regions, significant heterogeneity was found within each region where transit times varied by as much as 10 fold among tissue pieces.

As pointed out by Bassingthwaighte et al. (31), heterogene- 
ity at the fundamental microvascular unit can be estimated by measuring the relative dispersion at progressively smaller tissue sample sizes, thereby allowing the calculation of a fractal dimension. Assuming that the fractal relationship holds down to the level of the microvascular unit, and that the size of the unit is known, one could obtain information about spatial heterogeneity of flow at a physiologically relevant level. Such an analysis was impractical in our study for two reasons. First, the intrinsic heterogeneity in microvascular geometry and metabolic demand among the layers of the intestine wall would require separate consideration for each of these regions. Second, the size of the microvascular unit for the intestine is unknown, and is likely different in each of the layers. Although our study lacks such an approach, our tissue samples were small in volume compared with other studies (33), and the similar size permits comparisons across experiments.

Effects of changes in blood flow on heterogeneity. A number of previous investigators have examined the effect of changes in blood flow on the transit time heterogeneity in tissues. Using intravital microscopy in frog sartorius muscle exercising at a constant rate, Tyml and Mikulash observed an increased relative dispersion of perfusion when muscle blood flow was decreased by partial arterial clamping (34). Using indicator dilution methodology, Rose et al. estimated the effects of vasodilation and altered flow on capillary transit time heterogeneity in the coronary circulation (35). Although the number of experiments was small, their data suggest that an increase in blood flow was associated with a decrease in heterogeneity in a vascular bed that was previously vasodilated using papaverine. In a study of the coronary circulation, Cousineau et al. (36) found that increases in coronary blood flow, caused by carotid artery occlusion or pharmacological vasodilation, reduced the capillary transit time heterogeneity determined with indicator dilution analysis. However, direct comparisons to our study are complicated because our Low Flow stages were associated with $\mathrm{O}_{2}$ supply-limited conditions, unlike theirs. In our study, changing flow had no significant effect on the relative dispersion of blood flows, in either smooth muscle or mucosal pieces, under normovolemic or hypovolemic conditions. Thus, changes in blood flow had little influence on flow heterogeneity. However, we note that the amount of tissue receiving the lowest level of relative perfusion was consistently increased in the Low Flow compared with High Flow stages. This difference was evident in both mucosa and muscularis regions and may represent the onset of flow stagnation under low flow conditions. The appearance of such regions at low flow could begin to explain why $\mathrm{O}_{2}$ supply dependency begins in gut when $\mathrm{O}_{2}$ extraction generally is $<70 \%$.

Technical concerns. A mechanism not tested for in this study relates to the regulation of capillary surface area and the effects of reflex vasoconstriction on perfused capillary density. It is conceivable that reflex vasoconstriction could enhance capillary recruitment, or could act to better maintain capillary flow in the face of a decrease in tissue blood flow. Our observation that significant redistribution of blood flow occurred between mucosa and muscularis suggests that physiologically important vascular adjustments can occur without a change in gut vascular resistance. In either case, additional studies will be required to clarify the issue of capillary recruitment.

Studies by Maxwell et al. found that the distribution of microspheres in the gut wall shifted when isoproterenol was infused to produce vasodilation, or pump speed was increased to produce a $60 \mathrm{mmHg}$ increase in perfusion pressure (37). They suggested that redistribution could be minimized by sampling tissue immediately after infusing microspheres. While we did not follow this recommendation exactly, several aspects of our experimental design were intended to minimize the possibility of redistribution. First, the high flow stage was always done before low flow, so the adjustment always involved a subsequent decrease rather than an increase in pressure. Second, we used $15 \mu \mathrm{m}$ microspheres which showed less of a tendency to redistribute than $9 \mu \mathrm{m}$ spheres in their study. Third, we did not attempt to differentiate between muscularis and submucosal flows. Their data suggest that redistribution affects the submucosal flow measurement more than mucosal, so lumping of muscularis and submucosal tissues would have obscured any redistribution between these regions. Finally, the major hypotheses of our study were tested by comparing $\mathrm{O}_{2}$ extraction and regional perfusion under low flow conditions with normal and augmented vasoconstrictor tone. Microsphere distributions involved in these comparisons were sampled without any perturbations in flow or pressure after infusion, thus eliminating concern that any redistribution could have occurred. Moreover, the tissue was immersion fixed without allowing retrograde loss of blood volume, which could conceivable alter sphere localization.

We found that neither changes in flow nor changes in vasoconstrictor tone affected capillary transit time heterogeneity. It is possible that small changes did occur, but were not detected within a small $(n=6)$ group of studies. In smooth muscle, transit time heterogeneity increased after hemorrhage in four of six experiments and it decreased in two. In mucosa, heterogeneity increased in two animals, decreased in three, and was unchanged in one. The lack of any trend in the transit time heterogeneity response contrasts with the consistent response seen for the intramural redistribution of flow (Fig. 2) and suggests that any true changes in heterogeneity must have been small. Another possibility is that changes in heterogeneity occurred within the $100 \mathrm{mg}$ pieces of tissue. If so, these changes would not have been seen in our study but might be detectable using alternative methodology such as indicator dilution.

Significance. From the standpoint of tissue gas exchange, the distribution of capillary $\mathrm{O}_{2}$ delivery with respect to oxygen need is the most pertinent form of heterogeneity. Because no method yet exists to assess this, investigators instead have focused on quantifying the heterogeneity of blood flow with respect to tissue volume, while assuming that tissue oxygen demand is uniform. It is not clear whether the heterogeneity we found, which spanned more than a 10 -fold variation in relative perfusion, reflects an optimal matching to a widely varying $\mathrm{O}_{2}$ demand or an imperfect matching to a uniform tissue $\mathrm{O}_{2}$ demand. Insofar as this represents a true functional heterogeneity of $\mathrm{O}_{2}$ transport with respect to $\mathrm{O}_{2}$ need, our results may offer insight into the mechanism responsible for the decrease in tissue $\mathrm{VO}_{2}$ below the critical $\mathrm{O}_{2}$ delivery. Moreover, the contribution of increased transit time heterogeneity to the impaired tissue $\mathrm{O}_{2}$ extraction ability seen in models of sepsis is worthy of future study.

\section{Acknowledgments}

The authors gratefully acknowledge the technical assistance from Mr. Sang Choe in these studies. 
This work was supported by National Heart, Lung and Blood Institute grants HL35440 and HL32646; and by the Children's Research Foundation.

\section{References}

1. Cain, S.M. 1983. Peripheral oxygen uptake and delivery in health and disease. Clin. Chest. Med. 4:139-148.

2. Schumacker, P.T., and S.M. Cain. 1987. The concept of a critical oxygen delivery. Intensive. Care. Med. 13:223-229.

3. Granger, D.N., P.R. Kvietys, and M.A. Perry. 1982. Role of exchange vessels in the regulation of intestinal oxygenation. Am. J. Physiol. 242:G570G574.

4. Granger, H.J., A.H. Goodman, and B.K. Cook. 1975. Metabolic models of microcirculatory regulation. Fed. Proc. 34:2025-2030.

5. Cain, S.M. 1987. Gas exchange in hypoxia, apnea, and hyperoxia. In Handbook of Physiology: The Respiratory System Vol. IV, Section 3. A.P. Fishman, editor. American Physiological Society, Bethesda, MD. 403-420.

6. Samsel, R.W., and P.T. Schumacker. 1994. Systemic hemorrhage augments local $\mathrm{O}_{2}$ extraction in canine intestine. J. Appl. Physiol. 77:2291-2298.

7. Maginniss, L.A., H. Connolly, R.W. Samsel, and P.T. Schumacker. 1994. Adrenergic vasoconstriction augments tissue oxygen extraction during reductions in $\mathrm{O}_{2}$ delivery. J. Appl. Physiol. 76:1454-1461.

8. Buckberg, G.D., J.C. Luck, D.B. Payne, J.I. Hoffman, J.P. Archie, and D.E. Fixler. 1971. Some sources of error in measuring regional blood flow with radioactive microspheres. J. Appl. Physiol. 31:598-604.

9. Eckelman, W.C., R.C. Reba, and S.N. Albert. 1973. A rapid simple improved method for the preparation of $\mathrm{Tc}^{99 \mathrm{~m}}$ red blood cells for the determination of red cell volume. Am. J. Roentgenol. Radium Ther. Nuci. Med. 118:861864.

10. Weibel, E.R. 1979. Stereological Morphology. Academic Press Inc., Orlando, FL.

11. Humer, M.F., P.T. Phang, B.P. Friesen, M.F. Allard, C.M. Goddard, and K.R. Walley. 1996. Heterogeneity of gut capillary transit times and impaired gut oxygen extraction in endotoxemic pigs. J. Appl. Physiol. 81:895-904.

12. Thomas, L.J., Jr. 1972. Algorithms for selected blood acid-base and blood gas calculations. J. Appl. Physiol. 33:154-158.

13. Shepherd, A.P., and G.L. Riedel. 1985. Laser-Doppler blood flowmetry of intestinal mucosal hyperemia induced by glucose and bile. Am. J. Physiol. 248:G393-G397.

14. Hultén, L., J. Lindhagen, and O. Lundgren. 1977. Sympathetic nervous control of intramural blood flow in the feline and human intestines. Gastroenterology. 72:41-48.

15. Lundgren, O. 1991. Microcirculation of the gastrointestinal tract and pancreas. In Handbook of Physiology, Sec 2, Vol. 4, Part 2, The Microcirculation. E.M. Renkin and C.C. Michel, editors. American Physiological Society, Bethesda, MD.

16. Perry, M.A., and D. N. Granger. 1981. Permeability of intestinal capillaries to small molecules. Am. J. Physiol. 241:G24-G30.

17. Vallet, B., N. Lund, S.E. Curtis, D. Kelly, and S.M. Cain. 1994. Gut and muscle tissue $\mathrm{PO}_{2}$ in endotoxemic dogs during shock and resuscitation. J. Appl. Physiol. 76:793-800.
18. Shepherd, A.P. 1979. Intestinal $\mathrm{O}_{2}$ uptake during sympathetic stimulation and partial arterial occlusion. Am. J. Physiol. 236:H731-H735.

19. Lautt, W.W., and S.A. Graham. 1977. Effect of nerve stimulation on precapillary sphincters, oxygen extraction and hemodynamics in the intestines of cats. Circ. Res. 41:32-36.

20. McNeill, J.R., R.D. Stark, and C.V. Greenway. 1970. Intestinal vasoconstriction after hemorrhage: roles of vasopressin and angiotensin. Am. J. Physiol. 219:1442-1447.

21. Dodd, S.L., C.E. King, and S.M. Cain. 1987. Responses of innervated and denervated gut to whole-body hypoxia. J. Appl. Physiol. 62:651-657.

22. Hogg, J.C., B.A. Martin, S. Lee, and T. McLean. 1985. Regional differences in erythrocyte transit in normal lungs. J. Appl. Physiol. 59:1266-1271.

23. Rose, C.P., and C.A. Goresky. 1985. Limitations of tracer oxygen uptake in the canine coronary circulation. Circ. Res. 56:57-71.

24. Rose, C.P., and C.A. Goresky. 1976. Vasomotor control of capillary transit time heterogeneity in the canine coronary circulation. Circ. Res. 39:541554 .

25. King, R.B., J.B. Bassingthwaighte, J.R.S. Hales, and L.B. Rowell. 1985. Stability of heterogeneity of myocardial blood flow in normal awake baboons. Circ. Res. 57:285-295

26. Ellsworth, M.L., A.S. Popel, and R.N. Pittman. 1988. Assessment and impact of heterogeneities of convective oxygen transport parameters in capillaries of striated muscle: experimental and theoretical. Microvasc. Res. 35:341362.

27. Piiper, J., D.R. Pendergast, C. Marconi, M. Meyer, N. Heisler, and P. Ceretelli. 1985. Blood flow distribution in dog gastrocnemius muscle at rest and during stimulation. J. Appl. Physiol. 58:2068-2074.

28. Sparks, H.V., and D.E. Mohrman. 1977. Heterogeneity of flow as an explanation for the multi-exponential washout of inert gas from skeletal muscle. Microvasc. Res. 13:181-184.

29. Tyml, K. 1987. Red cell perfusion in skeletal muscle at rest and after mild and severe contractions. Am. J. Physiol. 252:H485-H493.

30. Honig, C.R., and C.L. Odoroff. 1981. Calculated dispersion of capillary transit times: significance for oxygen exchange. Am. J. Physiol. 240:H199H208,

31. Bassingthwaighte, J.B., R.B. King, and S.A. Roger. 1989. Fractal nature of regional myocardial blood flow heterogeneity. Circ. Res. 65:578-590.

32. Marcus, M.L., R.E. Kerber, J.C. Erhardt, H.L. Falsetti, D.M. Davis, and F.M. Abboud. 1977. Spatial and temporal heterogeneity of left ventricular perfusion in awake dogs. Am. Heart J. 94:748-754.

33. Allard, M.F., C.T. Kamimura, D.R. English, S.L. Henning, and B.R. Wiggs. 1993. Regional myocardial capillary erythrocyte transit time in the normal resting heart. Circ. Res. 72:187-193.

34. Tyml, K., and K. Mikulash. 1988. Evidence for increased perfusion heterogeneity in skeletal muscle during reduced flow. Microvasc. Res. 35:316-324.

35. Rose, C.P., C.A. Goresky, P. Belanger, and M.J. Chen. 1980. Effect of vasodilation and flow rate on capillary permeability surface product and interstitial space size in the coronary circulation. A frequency domain technique for modeling multiple dilution data with Laguerre functions. Circ. Res. 47:312-328.

36. Cousineau, D.F., C.A. Goresky, C.P. Rose, A. Simard, and A.J. Schwab. 1995. Effects of flow, perfusion pressure, and oxygen consumption on cardiac capillary exchange. J. Appl. Physiol. 78:1350-1359.

37. Maxwell, L.C., A.P. Shepherd, and G.L. Riedel. 1982. Vasodilation or altered perfusion pressure moves $15-\mathrm{mm}$ spheres trapped in the gut wall. Am. J. Physiol. 243:H123-H127. 